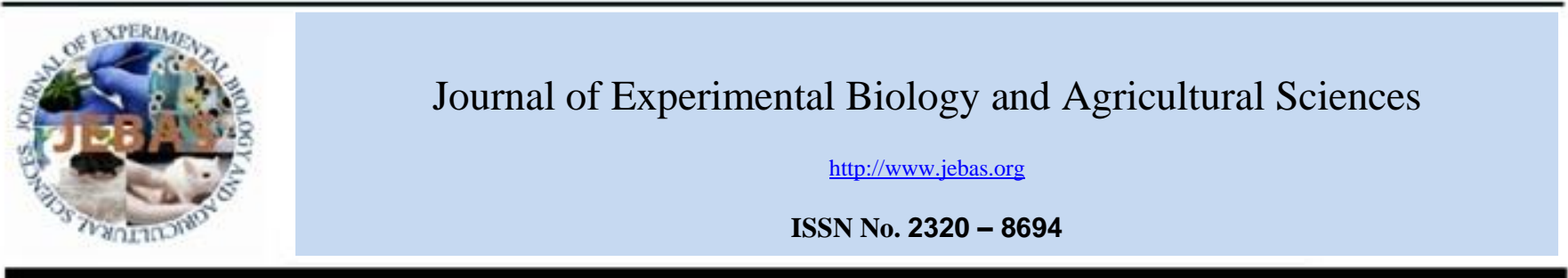

\title{
ASSESSING THE COMPETING ABILITY OF WEEDY RICE (Oryza sativa f. spontanea) WITH CULTIVATED RICE UNDER ELEVATED $\mathrm{CO}_{2}$ CONDITIONS
}

\author{
K. Anjali ${ }^{1}$, M. Ameena ${ }^{1 *}$, Nimmy Jose ${ }^{2}$, A. P.Pooja ${ }^{1}$, Fathima Umkhulzum ${ }^{1}$, S. Anjana ${ }^{1}$ \\ ${ }^{1}$ Department of Agronomy, College of Agriculture, Vellayani, Kerala (India)-695522 \\ ${ }^{2}$ Rice Research Station, Moncompu, Aleppey, Kerala 688503
}

Received - December 28, 2020; Revision - July 05, 2021; Accepted - July 13, 2021

Available Online - October 20, 2021

DOI: http://dx.doi.org/10.18006/2021.9(Spl-3-NRMCSSA_2021).S368.S371

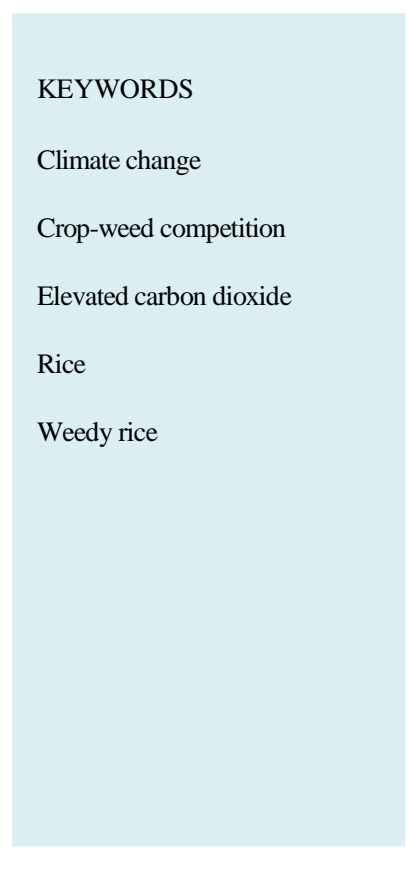

\begin{abstract}
Climate change can adversely affect rice production, especially for weed management in the context of emergence and proliferation of newer weed species like weedy rice (Oryza sativa f. spontanea) in the rice growing tracts of Kerala. In the past decade, atmospheric carbon dioxide $\left(\mathrm{CO}_{2}\right)$ has risen from 371.82 to 407.05 ppm from 2000 to 2018 which might have an impact on the competitive ability of a $\mathrm{C}_{3}$ plant like weedy rice. The competitiveness of weedy rice was studied in an open top chamber (OTC) under a $\mathrm{CO}_{2}$ concentration of $500 \mathrm{ppm}$ (Chamber A), OTC without external $\mathrm{CO}_{2}$ supply (Chamber B), and open condition along with two popular cultivated rice varieties Uma and Jyothi with both air and soil temperature inside the chamber to the tune of $40-43^{\circ} \mathrm{C}$ and $35-40^{\circ} \mathrm{C}$ respectively. The study revealed a higher competitive potential of weedy rice in terms of tillering ability under elevated carbon dioxide as it responded well compared to cultivated rice varieties. There was a differential response of rice varieties to elevated $\mathrm{CO}_{2}$ conditions with medium duration variety responding well compared to short duration one. Compared to ambient conditions (chamber B and open condition), higher tillering was observed under elevated $\mathrm{CO}_{2}$ (chamber A) in which weedy rice tillered profusely (17.33) than cultivated rice species ( 9 and 11.33). There was a linear increase in plant height of weedy rice in chamber A (108.97 $\mathrm{cm})$ during the initial stages and in chamber B $(112.77 \mathrm{~cm})$ during reproductive stages. The study evidenced that in the coming future, higher $\mathrm{CO}_{2}$ levels can stimulate biomass production of $\mathrm{C}_{3}$ weed like weedy rice with a greater increase in tillering which could be an important trait affecting inter specific competition.
\end{abstract}

* Corresponding author

E-mail: drameenaubaid@gmail.com (M. Ameena)

Peer review under responsibility of Journal of Experimental Biology and Agricultural Sciences.

Production and Hosting by Horizon Publisher India [HPI] (http://www.horizonpublisherindia.in/).

All rights reserved.
All the articles published by Journal of Experimental Biology and Agricultural Sciences are licensed under a Creative Commons Attribution-NonCommercial 4.0 International License Based on a work at www.jebas.org.

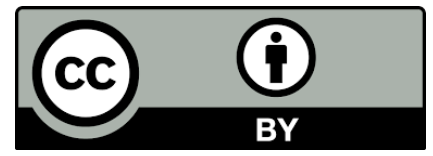




\section{Introduction}

Studies on the effects of climate change on rice production forecast negative effects. This necessitates a reformulation of crop management practices especially weed management because of the emergence and proliferation of newer weed species in rice. As environmental conditions have a huge impact on the effectiveness of weed management, newly emerged weed species like weedy rice (Oryza sativa f. spontanea) demands newer options in rice. Weedy rice has progressed primarily by natural hybridization between wild and cultivated rice and affects rice production, harvest quality, and income. With newer biotypes, weedy rice has infested the majority of rice growing areas in Asia and the main rice tracts of Kerala. This new weed has now invaded India with an infestation of 5 to $60 \%$ across different states. In Kerala, heavy infestation in recent years has caused a reduction in the yield by 30 to $60 \%$ (Seneweera et al., 1994; Abraham et al., 2012) depending on the severity of infestation (3 to 10 mature plants of weedy rice per square meter). Early flowering was observed in weedy rice compared to cultivated rice and it resulted in early grain maturing and seed shattering thus enhancing the weed seed bank (Anjali et al., 2018).

Atmospheric carbon dioxide $\left(\mathrm{CO}_{2}\right)$ has risen from 371.82 to $407.05 \mathrm{ppm}$ from 2000 to 2018 as a result of continuous anthropogenic activities and it is expected to reach $600 \mathrm{ppm}$ around 2050. As per the projections of the Intergovernmental Panel on Climate Change (IPCC), the atmospheric carbon dioxide concentration is expected to reach 730 to $1020 \mathrm{ppm}$ by 2100 (Meehl et al., 2007). Studying crop weed response in elevated $\mathrm{CO}_{2}$ conditions will help to assess the nature of weediness in rice production systems in the era of climate change. In this background, the present study was undertaken to assess the impact of climate change, particularly elevated $\mathrm{CO}_{2}$ and higher temperature on the growth and competitiveness of weedy rice in the rice production system.

\section{Materials and Methods}

The experiment on the competitiveness of weedy rice was conducted in open top chambers (OTC) maintained under a carbon dioxide concentration of $500 \mathrm{ppm}$ called chamber $\mathrm{A}$ and another without carbon dioxide called chamber B. Both air and soil temperatures inside the chamber were to the tune of $40-43^{\circ} \mathrm{C}$ and 35- $40^{\circ} \mathrm{C}$, respectively. Pre-germinated seeds of Jyothi, Uma, and weedy rice were sown in plastic pots filled with clayey soil collected from rice fields and transferred to OTC at 10 DAS. A flooded situation was maintained throughout the crop growth period. The experimental design used was a completely randomized design with nine treatments replicated thrice inside OTC. The treatments were Jyothi in Chamber A $\left(\mathrm{T}_{1}\right)$, weedy rice in Chamber A $\left(\mathrm{T}_{2}\right)$, Uma in Chamber A $\left(\mathrm{T}_{3}\right)$, Jyothi in Chamber B
$\left(\mathrm{T}_{4}\right)$, weedy rice in Chamber B $\left(\mathrm{T}_{5}\right)$, Uma in Chamber B $\left(\mathrm{T}_{6}\right)$, Jyothi under open condition $\left(\mathrm{T}_{7}\right)$, weedy rice under open condition $\left(\mathrm{T}_{8}\right)$ and Uma under open condition $\left(\mathrm{T}_{9}\right)$. After panicle emergence weedy rice panicles were separately bagged to prevent the shattering of grains. Panicles from weedy rice, Jyothi, and Uma were harvested separately, grains removed and yield was recorded. All the yield attributing characters were observed separately for Uma, Jyothi, and weedy rice at 30 DAS and $50 \%$ flowering. The data recorded were subjected to statistical analysis.

\section{Results and discussion}

\subsection{Effect of elevated $\mathrm{CO}_{2}$ conditions on rice and weedy rice growth attributes}

The study revealed significant variations in vegetative attributes of rice and weedy rice under elevated $\mathrm{CO}_{2}$ levels (Table 1). However, the extent of response varied among the cultivars under varying atmospheric situations. Of the various growth and yield attributes analyzed, weedy rice responded well to elevated carbon dioxide compared to cultivated rice showing its higher competitive potential. Ziska et al. (2010) reported that weedy rice responds more strongly to rising carbon dioxide levels than cultivated rice with its greater competing ability suggesting the magnitude of weedy rice as a problem weed in the future rice production system. There was a differential response between rice varieties to elevated $\mathrm{CO}_{2}$ conditions with Uma responding well compared to Jyothi.

Elevated $\mathrm{CO}_{2}$ had a significant influence on plant height in both rice and weedy rice in all three situations. There was a linear increase in plant height of weedy rice in chamber A during the initial stages and in chamber B during reproductive stages. This indicated that weedy rice responded well to elevated $\mathrm{CO}_{2}$ condition during the initial stages and at the reproductive stage, the response was more to the ambient conditions of chamber B. Singh \& Jasrai (2011) reported that effects of elevated $\mathrm{CO}_{2}$ to plant growth was more pronounced during early growth stages and reduced greatly at later stages. On analyzing the plant height, the response between cultivated rice and weedy rice it was observed that Jyothi responded well under elevated $\mathrm{CO}_{2}$ conditions as compared to the Uma.

Tillering ability of both weedy rice and cultivated rice was significantly affected by various growing situations. Compared to ambient conditions (chamber $\mathrm{B}$ and open condition), higher tillering was observed under elevated $\mathrm{CO}_{2}$ (chamber A) in which weedy rice tillered profusely (17.33) than cultivated rice species $(9$ and 11.33 for Jyothi and Uma respectively). The results of the present study are in confirmation with the findings of Ziska et al. (2010), who reported that weedy rice responded more strongly to rising $\mathrm{CO}_{2}$ levels than cultivated rice with greater competing ability. In Kerala, 60 percent of kharif crop is raised under direct 
Table 1 Performance of rice varieties and weedy rice under elevated $\mathrm{CO}_{2}$ in ambient and open conditions

\begin{tabular}{|c|c|c|c|c|c|c|c|}
\hline Chambers & Treatments & $\begin{array}{l}\text { Plant height } \\
\quad(\mathrm{cm})\end{array}$ & $\begin{array}{c}\text { No of tillers } \\
\text { at } 30 \text { DAS }\end{array}$ & $\begin{array}{l}\text { No of tillers at } \\
50 \% \text { flowering }\end{array}$ & $\begin{array}{c}\text { Days to } 50 \% \\
\text { flowering (Days) }\end{array}$ & $\begin{array}{l}\text { Number of grains } \\
\text { per panicle }\end{array}$ & $\begin{array}{c}\text { Grain yield } \\
\text { per plant }(\mathrm{g})\end{array}$ \\
\hline \multirow{3}{*}{ Chamber A } & Jyothi $\left(\mathrm{T}_{1}\right)$ & 96.17 & 3.00 & 9.00 & 61.78 & 100.00 & 7.22 \\
\hline & Weedy rice $\left(T_{2}\right)$ & 108.97 & 3.67 & 17.33 & 45.97 & 63.67 & 9.88 \\
\hline & $\operatorname{Uma}\left(\mathrm{T}_{3}\right)$ & 90.72 & 3.33 & 11.33 & 77.57 & 114.00 & 17.75 \\
\hline \multirow{3}{*}{ Chamber B } & Jyothi $\left(\mathrm{T}_{4}\right)$ & 98.16 & 3.33 & 9.33 & 62.28 & 95.67 & 6.80 \\
\hline & Weedy rice $\left(T_{5}\right)$ & 112.77 & 3.33 & 13.33 & 48.27 & 60.08 & 6.79 \\
\hline & $\operatorname{Uma}\left(\mathrm{T}_{6}\right)$ & 91.06 & 3.33 & 8.67 & 79.69 & 105.00 & 14.36 \\
\hline \multirow{5}{*}{$\begin{array}{c}\text { Open } \\
\text { condition }\end{array}$} & Jyothi $\left(\mathrm{T}_{7}\right)$ & 92.43 & 2.00 & 4.33 & 67.78 & 98.33 & 9.28 \\
\hline & Weedy rice $\left(T_{8}\right)$ & 105.07 & 2.33 & 6.00 & 51.57 & 48.33 & 5.70 \\
\hline & $\operatorname{Uma}\left(\mathrm{T}_{9}\right)$ & 88.37 & 1.00 & 3.33 & 81.88 & 90.67 & 8.62 \\
\hline & $\operatorname{SE}( \pm)$ & 1.43 & 0.27 & 1.09 & 0.34 & 3.93 & 1.06 \\
\hline & $\operatorname{LSD}(0.05)$ & 4.26 & 0.81 & 3.26 & 1.02 & 11.67 & 3.15 \\
\hline
\end{tabular}

seeding in the rainfed situation. Weedy rice being a serious problem in direct seeded rice system, the production system turns more vulnerable to direct effects of climate change in terms of increased competition from weedy rice. Though for a $\mathrm{C}_{3}$ crop like rice, elevated $\mathrm{CO}_{2}$ levels may favour crop competitiveness, the dynamics take a reverse turn with weedy rice. Amongst the cultivars, Uma showed better response to elevated $\mathrm{CO}_{2}$ producing tillers thrice than in open conditions. However, Jyothi was found less responsive to elevated $\mathrm{CO}_{2}$ levels in terms of tiller production indicating variation in varietal response to carbon dioxide levels.

3.2 Yield attributes of rice and weedy rice influenced by elevated $\mathrm{CO}_{2}$ conditions

Earliness in flowering was observed under elevated $\mathrm{CO}_{2}$ conditions for both weedy rice (45.97 days) and cultivated rice compared to open condition (51.57 days) (Table 1). Compared to the open condition, weedy rice recorded an earliness of 15 and 7 days in Chamber A and B respectively, indicating the favourable effect of elevated $\mathrm{CO}_{2}$ on flowering. Chauhan et al. (2014), observed that climate change not only affects the crop-weed competition but also triggers early flowering and weed seed germination in several flushes causing serious weed management issues. This earliness in the flowering of weedy rice might help to complete its life cycle faster and initiation of more life cycles even within a single crop period. Jyothi and Uma also recorded an earliness of 17 and 8 days in Chamber A and B respectively. Hence, it could be concluded that early flowering induced from elevated carbon dioxide levels would contribute to more weed seed banks and might pose serious threats to rice cultivation in the future.

The number of grains per panicle was found to increase with the increase in $\mathrm{CO}_{2}$ levels. Weedy rice recorded a greater response to the number of grains per panicle in chamber A with a percentage increase of 20.69 to 24.09 . Kim et al. (2003) reported a linear relationship between elevated $\mathrm{CO}_{2}$ and spikelet number. Varietal variations were observed with Jyothi recording a poor response and Uma exhibiting a greater response to elevated $\mathrm{CO}_{2}$ concentration. But this conflicted with the findings of Sherchand \& Sharma (2004), who reported that elevated $\mathrm{CO}_{2}$ had little effect on the number of grains per panicle. Though Uma recorded the highest number of grains per panicle (114) compared to weedy rice (64) and Jyothi (100), the percentage increase in the number of grains per panicle was greatest for weedy rice under elevated $\mathrm{CO}_{2}$ conditions.

Grain yields varied under various $\mathrm{CO}_{2}$ concentrations, for weedy rice with a higher grain yield per plant in Chamber A followed by Chamber B which were 1.73 and 1.19 times respectively than open condition. Uma showed a greater percentage increase in grain yield (51.4\% in chamber A and $40 \%$ in chamber B) followed by weedy rice $(42.3 \%$ in chamber $\mathrm{A}$ and $16 \%$ in chamber $\mathrm{B})$. The higher grain yield of Uma was a result of the greater number of grains per panicle, lower sterility percentage, and higher thousand grain 
weight. Similar results were also reported by Uprety et al. (2003) and Sherchand \& Sharma (2004). Jyothi recorded a negative response to elevated $\mathrm{CO}_{2}$ levels. A significant variation was observed between chambers, indicating the effect of elevated $\mathrm{CO}_{2}$ on grain yield. This increase in grain yield might be due to an increase in the number of grains per panicle under elevated levels of $\mathrm{CO}_{2}$.

\section{Conclusion}

From the results of the study, it could be concluded that weedy rice responded more strongly to rising $\mathrm{CO}_{2}$ conditions than cultivated rice during the initial stages as evidenced by the higher plant height and profuse tillering. It is apparent that in the future, the higher concentration of $\mathrm{CO}_{2}$ in the atmosphere might enhance the competitive ability of weedy rice plants with deleterious effects on rice production.

\section{Conflict of interest}

The authors declare no conflict of interest.

\section{References}

Abraham CT, Jose N, Rathore M (2012) Current status of weedy rice in India and strategies for its management. In: Biennial Conference of ISWS on Weed Threat to Agriculture, Biodiversity and Environment, 19-20 April, 2012; Kerala Agricultural University, Thrissur, Pp. 8-12.

Anjali K, Ameena M, Jose N (2018) Management of weedy rice (Oryza sativa f. spontanea) by enhancing rice competitiveness. Journal of Crop Weed 14(3): 130-135.
Chauhan BS, Mahajan G, Randhawa RS, Singh H, Kang MS (2014) Global warming and its possible impact on agriculture in India. Advances in Agronomy 123: 65-121.

Kim JC, Lee DW, Kim YH, Son SY (2003) Effect of duration of competition and density of red rice on growth and yield of rice. Korean Journal of Crop Science 7: 45-51.

Meehl G, Washington WM, Collins WD (2007) How much more global warming and sea level rice. Science 307: 1769-72.

Seneweera S, Makino A, Mae A, Basra AS (1994) Response of rice to $\left(\mathrm{CO}_{2}\right)$ enrichment: The relationship between photosynthesis and nitrogen metabolism. Journal of Crop Improvement 13: 31-53.

Sherchand JB, Sharma PR (2004) Crop performance and water and nitrogen use efficiencies in dry seeded rice in response to irrigation and fertilizer amounts in northwest India. Field Crops Research 134: 59-70.

Singh N, Jasrai K (2011) Allelopathy for weed control in agricultural systems. Crop Protection 72: 57-65.

Uprety DC, Dwivedi N, Jain V, Mohan R, Saxena DC, Jolly M, Paswan G (2003) Response of rice cultivars to the elevated $\mathrm{CO}_{2}$. Biologia Plantarum 46(1): 35-39.

Ziska LH, Tomecek MB, Gealy DR (2010) Competitive interactions between cultivated and red rice as a function of recent and projected increase in atmospheric carbon dioxide. Agronomy Journal 102: 118-123. 